\title{
Um balanço da Reforma Psiquiátrica Brasileira: Instituições, Atores e Políticas
}

\author{
An assessment of Brazilian Psychiatric Reform: \\ Institutions, Actors and Policies
}

Ana Maria Fernandes Pitta ${ }^{1}$

\footnotetext{
${ }^{1}$ Universidade de São Paulo Av. Dr. Arnaldo 455, Cerqueira César. 01246-903 São Paulo SP. anapitta@usp.br
}

\begin{abstract}
The article takes a look at Brazilian Psychiatric Reform over the past decade, after the approval of Federal Law 10.216/2001 and seeks to elicit long overdue discussion about the pressing challenges that Brazilian Psychiatric Reform needs to tackle to promote or review the long-desired utopia of "full citizenship for all in a society without asylums." Is the Reform showing signs of exhaustion? The redirection of the care model for Mental Health in Brazil from the hospital to the community over the past decade is an undeniable achievement. Taking the use of psychoactive substances as the scope of policy and intervention, this incorporates complex demands that the current Crack drama makes it more urgent to question its history, its limits, its power. What will keep the flame alight of a successful movement that, surprisingly, has resisted the force of time and stigma in the ten years since the Law was enacted? These and other questions need to be worked on. It is time to recycle the focus of assessment and anal$y$ sis in order to identify what threatens its vitality. This is the challenge to which the writer and debaters will be enjoined to contribute.
\end{abstract}

Key words Psychiatric reform, Mental Health policy, Human Rights
Resumo O artigo provoca olhares sobre a Reforma Psiquiátrica Brasileira (RPB) na última década, após a homologação da Lei Federal 10.216/ 2001 e pretende suscitar o debate inadiável sobre os novos desafios que ela precisa enfrentar para alimentar ou reciclar a antiga utopia de "cidadania plena para todos, numa sociedade sem manicômios". Estaria a Reforma dando sinais de exaustão? É inegável a reorientação do modelo assistencial de Saúde Mental no Brasil do hospital para a comunidade nessa última década. Ao tomar o uso de Substâncias Psicoativas como objeto de politicas e intervenção, incorpora demandas complexas que o atual drama do Crack somente imediatiza a necessidade de questionar sua história, seus limites, sua potência. O que manterá acesa a chama de um movimento exitoso que, surpreendentemente, resiste à força do tempo e do estigma nesses dez anos da Lei? Essas e outras questões precisam ser equacionadas. Está na hora de reciclar os focos de avaliação e análise no sentido de identificar o que ameaça sua vitalidade. Esse é o desafio que a articulista e debatedores estarão provocados a contribuir.

Palavras Chaves Reforma psiquiátrica, Politica de Saúde Mental, Direitos Humanos 


\section{Contexto}

Após anos de resistência cívica e vitórias acumuladas estaria a Reforma Psiquiátrica Brasileira (RPB) dando sinais de exaustão? Foram décadas de crescimento de um movimento social desigual, constante e jamais visto no Brasil e no mundo em torno da luta por Direitos Humanos fundamentais “dos loucos de todo o gênero". Nessa última década muitas de suas bandeiras de luta se tornaram realidade no país. Os Centros de Atenção Psicossocial (CAPS), os Serviços Residenciais Terapêuticos (SRT), o Auxílio de Reabilitação Psicossocial "De volta pra casa”, expandiram, significantemente, a possibilidade de desinstitucionalização responsável de pessoas submetidas a longos períodos de internações psiquiátricas, ao tempo que se assistiu a uma redução expressiva de leitos em hospitais psiquiátricos, particularmente nos estados do sudeste e nordeste brasileiro. $\mathrm{Pa}$ ralelamente se solidifica um modelo de atenção psiquiátrica baseado na comunidade e não centrado no hospital como a escolha da política pública de saúde mental no país.

Estaria assim o movimento da Reforma Psiquiátrica sendo fagocitado pela força democratizante de gestões de Municípios, Estados e União, na medida em que alguns de seus mais expressivos militantes assumiram funções públicas relevantes no interior do aparelho de Estado? Ao incorporar as clássicas bandeiras do movimento da luta antimanicomial, como o fechamento dos manicômios e o aumento da acessibilidade ao cuidado mental comunitário, os governos democráticos a teriam esvaziado dos seus lemas mais mobilizadores? Entretanto, outro aspecto a se considerar seria se os militantes reformistas estariam se consumindo em batalhas fratricidas, fragmentados em grupos e facções que se anulam na ação política comum que deveria fazer avançar a Reforma, deixando frágil o movimento social que foi o motor de mudanças na Legislação, nas políticas públicas, no enfrentamento do estigma da loucura na sociedade.

Por outro olhar, essa aparente fragmentação de ações e propósitos poderia ser vista como a estratégia mais competente para atravessar a crise de crescimento do movimento da Reforma e as novas provocações que as conquistas alcançadas pelo próprio movimento vão acrescentando a demandas já tão complexas. Acompanhada sempre por um volume importante de frustrações e desesperanças com a lentidão e as respostas negativas dos governos e da sociedade, a RPB vai assumindo características das redes inteligentes de Pier- re Levi com diferentes e fractais focos de atuação na Saúde, na Cultura, na Justiça, na Previdência, na geração de renda e trabalho, nas Artes, buscando ser intersetorial por excelência. E um bom exemplo dessa nova vitalidade multifacetada seria o sucesso da "marcha dos usuários em Brasília” em setembro de 2010, que conseguiu mobilizar e pacificar interesses antagônicos dos diferentes grupos para a convocação da IV Conferência de Saúde Mental Intersetorial, realizada em dezembro do mesmo ano, fazendo resgatar uma democracia participativa há muito não vista.

Escrever sobre uma história recente onde se é também protagonista e se pretende, isenta de paixões, sustentar as controvérsias de uma era turbinada da política de Saúde Mental do Brasil é missão quase impossível. Impõe-se compartir com outros, também atores e expostos aos mesmos riscos, como estratégia única de reduzir os perigos de um etnocentrismo nocivo e previsto. E não está eliminado o prejuízo que uma dialética imperfeita "da perversidade natural do gênero humano" de fazer "aferrar-se à razão, quando não se tem" ${ }^{1}$, no esforço de seguir o dever da crítica. Ainda não conseguimos assegurar o cuidado das crises psicóticas ou das demandas de fissura e abstinência de usuários de crack em situação de rua se os serviços ambulatoriais e comunitários cerram suas portas às cinco da tarde na sua grande maioria. O que fazer quando a noite vem? Continua o manicômio no imaginário coletivo como o abrigo seguro para as situações críticas? Extremo retrocesso!

Já existem no país, corroborando estudos internacionais, evidências de níveis de efetividade individual e social maiores para pessoas com transtornos mentais que estão sendo tratadas na comunidade, se comparadas àquelas tratadas em regime de privação de liberdade ${ }^{2-9}$.

As últimas Conferências de Saúde Mental, municipais, estaduais e nacionais, populosas e participativas, trazem quase como uníssona a voz de usuários e trabalhadores de saúde clamando pela condenação dos manicômios e pela defesa da "liberdade terapêutica". Porque então ainda não alcançamos um consenso de como agir se já temos uma unanimidade discursiva onde ninguém mais ousa defender explicitamente os manicômios como estratégia preferencial de cuidados em psiquiatria e saúde mental?

Mesmo que na prática ajam de modo a boicotar o crescimento e a qualificação dessa rede comunitária e evoquem, de modo nostálgico, os leitos psiquiátricos perdidos no processo da $R e$ forma, todos advogam uma diversificação de ser- 
viços comunitários no território para enfrentar a complexidade dos transtornos mentais e do uso de substâncias psicoativas, e condenam as condições desumanas que muitos hospitais seguem dispensando a seus usuários. Entretanto, observamos que o confinamento e a exclusão da loucura e do uso abusivo de drogas está presente entre políticos, legisladores, gestores, acadêmicos, mídia e no imaginário de setores hegemônicos da sociedade. E é contrário a esses nichos conservadores que o movimento da Reforma Psiquiátrica segue se insurgindo como "processo político e social complexo, composto de atores, instituições e forças de diferentes origens, que incide em territórios diversos... nas associações de pessoas com transtornos mentais e de seus familiares, nos movimentos sociais"10.

Entre os grupos contra e a favor da Reforma, nos governos, na sociedade civil e na população em geral, o estigma contra o louco persiste e de vários modos, explícitos ou sutis. Evidências disso são localizadas na não escuta e não credibilidade da palavra dessas pessoas, gerando uma crônica postergação de suas demandas. Também presente num certo descompromisso ético-político por parte de profissionais de saúde, profissionais do direito, da previdência e assistência social, que administram com ambiguidade a ideia de uma sociedade onde o louco e o usuário de substâncias psicoativas sejam pares, parceiros na definição de políticas e nos seus próprios tratamentos.

A crise das políticas públicas que as deixam "fora de moda" talvez explique porque, mesmo quando se alcança algum consenso para o cuidado em liberdade, não se responda prontamente às vulnerabilidades e fragilidades das pessoas em sofrimento nas práticas de saúde e intersetoriais existentes. As demandas da saúde mental seguem sendo postergadas: primeiro as criancinhas, depois os velhinhos, a saúde da mulher (como aparelho reprodutor), mais recentemente a dos homens, porque andam morrendo mais e ameaçando a economia e a previdência social. E os programas de saúde pública se organizam sempre nas suas vertentes fisicalistas, sem direito à subjetivação. As sutilezas do estigma presentes nas campanhas midiáticas de governos tipo "crack: cadeia ou caixão" banalizam o apocalíptico e induzem a um mero "não ter o que fazer" cômodo e paralizante.

“... é preciso avançar na elaboração de dispositivos teóricos e de formas de ação que ao mesmo tempo retenham o horizonte fundamental da clínica ... e ampliem o alcance da rede" ${ }^{11}$.

\section{As instituições...}

O maior desafio da saúde mental e da clínica psiquiátrica é não ter o clinos=leito como avatar de sua "boa prática"12 e, uma vez ele sendo necessário deve estar acessível e disponível de modo descentralizado, no território, onde o paciente estiver. Pensar sua oferta na rede de hospitais gerais e comunitários espalhados pelo país e dotar os CAPS de leitos disponíveis, funcionando em tempo integral, utilizando uma mais ampla capilaridade e presença nos municípios, é o que seria mais útil. Seguramente será a forma mais efetiva e eficaz de garantir a hospitalidade diuturna, integral e resolutiva, onde a crise ocorrer. Como afirma Domingos Sávio Alves: "a boa assistência em saúde mental precisa menos de leitos e sim de vagas"13.

A advertência de Mari e Thornicroft ${ }^{14}$ de "evitar o fechamento de um hospital psiquiátrico antes que um serviço comunitário de assistência esteja solidamente estabelecido na mesma área" é mais que pertinente desde que se registre o fato de que a criação desses leitos psiquiátricos no Brasil não obedeceu a qualquer planejamento de cobertura populacional. Alta concentração de leitos psiquiátricos, não justificados, em algumas regiões do país e, nenhuma oferta na maioria delas foi a justa medida de um planejamento perverso, onde mais valeu o privilégio de alguns beneficiários diretos e indiretos do poder instituído, que das pessoas em sofrimento, a terem suas necessidades cobertas ${ }^{15}$. Percorrer esse mesmo traçado na implantação dos novos serviços seria perpetuar uma distorção. O direito universal de atenção à saúde mental e assistência psiquiátrica devem acompanhar as necessidades dos moradores dos 5.645 municípios do país. O que assistimos nessa última década foi ao aparecimento de serviços de Saúde Mental tipo CAPS (1.645) em vários municípios até então não cobertos, embora ainda tenhamos muitos vazios assistenciais que merecem um enfrentamento corajoso do Estado para que o país atinja uma cobertura assistencial decente ${ }^{16}$.

$\mathrm{O}$ aumento da acessibilidade ao cuidado em Saúde Mental na última década, no território nacional, após a aprovação da Lei, é fato inquestionável (vide Tabela 1) e merece avançar uma vez que ainda não dispomos de um patamar satisfatório de recursos assistenciais no país.

\section{Os Atores...}

Não é consenso o lugar, o tempo e os atores que desencadeiam a Reforma Psiquiátrica Brasi- 
Tabela 1. Saúde mental em Dados 2002-2010

\begin{tabular}{lrrr}
\hline \multicolumn{1}{c}{ Indicadores } & \multicolumn{1}{c}{$\mathbf{2 0 0 2}$} & $\mathbf{2 0 1 0}$ & Observação \\
\hline CAPS - Centros de Atenção Psicossocial & 424 & 1650 & \\
SRT - Serviços Residenciais Terapêuticos & 85 & 570 & \\
"De volta pra casa" - benefícios de Reabilitação & $206^{*}$ & 3.635 & * começa em 2003 \\
Geração de Renda e Trabalho - Projetos & $151^{*}$ & 640 & * começa em 2005 \\
Leitos em Hospitais Psiquiátricos & 51.393 & 32.735 & \\
Gastos com Saúde Mental em Reais & 24.293 .39 & 58.270 .26 & \\
Percentual de gastos da saúde mental no SUS & 2,55 & 2,57 & \\
\hline
\end{tabular}

Fontes: Coordenação de Saúde Mental, Álcool e Outras Drogas/DAPES/SAS/MS, SIH/SUS, PRH/CNES e Coordenações Estaduais.

leira. Consenso maior considera o processo de democratização do país no final da década de 1970, trazendo os movimentos sociais com suas diferentes estratégias e em diferentes estados do país para transformar políticas e instituições desumanas, como o possível marco inicial. Nessa era de Reformas tivemos dois movimentos sócio-políticos mais determinantes dessa transição: na Saúde em geral a Reforma Sanitária, e na Saúde Mental a Reforma Psiquiátrica, que conviveram e se alimentaram da mesma efervescência político-participativa e democratizante da época ${ }^{17}$.

Entre os anos de 1975 a 1980 o Movimento da Reforma Psiquiátrica Brasileira recebia da Europa em São Paulo, Rio de Janeiro, Salvador, Belo Horizonte e Barbacena insumos importantes para abastecer seus ideais reformistas: Franco Basaglia, Michel Foucault, Ronald Laing, Felix Guattari, Robert Castel vinham para Congressos, Seminários em Universidades, em missões éticopolíticas cativantes, trazendo informações e levando notícias nossas; testemunhando e reconhecendo grupos de resistência, instigando jovens inquietos (alguns presentes nesse debate) para movimentos sociais como a defesa dos direitos dos enfermos mentais, condições e processo de trabalho em instituições manicomiais, na contribuição teórico-crítica em diferentes cenários acadêmicos, associativos, sindicais, estudantis.

No limite, todos, de todas as profissões, querem condições ideais de atendimento aos enfermos, e melhores condições de trabalho para si. Entretanto, atualmente, muitos desses profissionais que poderiam fazer a diferença em termos de implicação ética e técnica com a "boa prática", para sustentar a interdisciplinaridade por consequência a potência das equipes nos territórios, parecem desconhecer, ou não se sentem convocados, ao apelo ético-político desses primeiros momentos. Existe uma paradoxal estratégia defensiva de fuga da responsabilidade na constru- ção de "uma clínica em movimento" ${ }^{18}$. Cuidado este sustentado numa ética de corresponsabilidade que estende e muito o alcance das intervenções em crises nos serviços comunitários quando a equipe consegue perceber a importância da contribuição de cada um dos seus integrantes. Tais espaços de trabalho dependem fortemente desses profissionais para "o tomar a si a responsabilidade de cuidar”, numa ação transdisciplinar potente. O lugar simbólico do medicamento e do médico na relação com o usuário é algo que precisa ser trabalhado, valorizado, e a um só tempo, desmistificado por esses profissionais. O enfrentamento do "modelo médico hegemônico", tão decantado, vai significar uma clínica implicada de atenção à crise e à cotidianidade dos sujeitos desempenhada por todos os integrantes de uma equipe de "serviços substitutivos" ao manicômio. Mais ainda e lembrando Luiz Cerqueira, psiquiatra, professor de psiquiatria, coordenador nacional de Saúde Mental nos anos setenta: "a saúde mental é coisa muito séria para estar confiada em mãos apenas de psiquiatras"! Bem reflete quanta humildade e corresponsabilidade são necessárias para se trabalhar nesse campo.

\section{A propósito, as Políticas...}

Com a entrada em cena de movimentos sociais de profissionais, trabalhadores, usuários, familiares, militantes dos Direitos Humanos, prestadores públicos e privados, gestores, sindicatos e associações, nos fins dos anos setenta, o movimento da Reforma nasce ganha maior visibilidade e força ${ }^{19}$ e também produz seus mais ferrenhos inimigos. E não existe estratégia mais potente para criar coesão de um grupo ou de um movimento do que ter inimigos comuns contra quem lutar! A ditadura militar, a não democracia, o interesse mercantil dos industriais da loucura, forjaram o cenário favorável ao surgimento de 
múltiplos focos de movimentos sociais em torno dos maus tratos aos usuários de instituições psiquiátricas manicomiais no Brasil. Considerando as mudanças políticas importantes ocorridas no país, que antecedem a aprovação da Lei 10.216/ 21 , recortemos em décadas seus fatos mais significativos para melhor contextualizar a trajetória da Reforma embora tenhamos claro que a história como a vida "vem em ondas como o mar" e sempre persistem resíduos de etapas anteriores enquanto tempo e movimento avançam.

\section{Os anos 70 - a denúncia}

Tempos de característica hegemonicamente asilo-manicomial na assistência aos doentes mentais no Brasil, que experimentou nessa década uma grande expansão das internações psiquiátricas a grupos cada vez maiores da população, após a unificação dos Institutos de Aposentadorias, em 1966, centralizando recursos com a criação do Instituto Nacional de Previdência Social (INPS). Boas idéias no Ministério da Saúde, que não tinha dinheiro para implementá-las e muito dinheiro no INPS, no Ministério da Previdência Social, que o utilizava ao bel prazer da conjuntura e do Ministro de plantão sem que o emergente movimento social fosse escutado. $\mathrm{Na}$ era da "indústria da loucura”, em plena ditadura militar, se construía manicômios cada vez maiores e mais lucrativos sustentados por recursos públicos. O fluxo do dinheiro público para a esfera privada nesse período é revelado no fato de que, entre 1965 e 1970 a população internada em hospitais públicos permaneceu a mesma, enquanto a clientela das instituições conveniadas remuneradas pelo poder público saltou de 14 mil, em 1965, para trinta mil em $1970^{20}$. Anos depois, esses números se multiplicariam para 98 mil leitos psiquiátricos em 1982, concentrados na região sudeste e em alguns estados do nordeste ${ }^{14}$, mantendo uma proporção de $80 \%$ de leitos contratados junto ao setor privado e $20 \%$ diretamente públicos ${ }^{21}$.

Por outro lado, quase clandestinos, os militantes da RPB, insatisfeitos com o sistema psiquiátrico vigente, brigavam subterraneamente onde era possível brigar: congressos, associações, sindicatos, redes, constituindo-se como movimentos sociais.

\section{Os anos 80 - tempos de "fazejamentos"}

Já ao final dos anos 70, o movimento pelas Reformas na assistência em Saúde e da Saúde Mental caminhou junto aos movimentos sociais de usuários e familiares. Quanto à incorporação desses novos protagonistas, o já denominado Movimento pela Reforma Psiquiátrica Brasileira vai acumulando força e experiência: 1 - no Encontro Brasileiro da Rede de Alternativas à Psiquiatria em 1983 em Belo Horizonte, MG com mais de mil e quinhentos participantes; 2 - no I Congresso de Trabalhadores de Saúde Mental de São Paulo, em 1985, em São Paulo, com mais de mil participantes, organizado sem participação do movimento social, que ensinou a todos que o processo de democratização em curso no país determinava que não mais poderia ser assim (existiram dois "primeiros Congressos", sendo que apenas o segundo, organizado pela emergente Plenária de Trabalhadores de Saúde Mental foi reconhecido como tal pelo movimento social). Ambos aconteceram no Centro de Convenções Rebouças, na cidade de São Paulo, ambos com mais de mil participantes, mas havia a alegria participativa no segundo para compensar a tensão do jejum democrático do primeiro I Congresso de Trabalhadores de Saúde Mental; 3 - na I Conferência Nacional de Saúde Mental em 1987 no Rio de Janeiro, também organizada sem o movimento social e igualmente cenário de desobediência civil pelo movimento da Reforma; 4 - no posterior II Encontro Nacional dos Trabalhadores em Saúde Mental, em Bauru, São Paulo, (terceiro na cronologia e primeiro no significado histórico-social, já organizado pelo movimento social com apoio da municipalidade). É o Congresso de Trabalhadores de Bauru, realizado em 1987 que alcança o consenso de ser o marco de articulação de diferentes movimentos sociais em torno da Reforma Psiquiátrica, particularmente de São Paulo, Rio, Minas Gerais, onde se pactuou o lema "por uma sociedade sem manicômios" originado na Itália, trazido do último encontro da Rede de Alternativas à Psiquiatria que animou e parece seguir animando a utopia da Reforma Psiquiátrica Brasileira. "A realização desse encontro foi decidida durante a I Conferência, pela constatação de que a perspectiva sanitarista de incorporar as propostas reformistas nas políticas oficiais vinha sendo anulada pela resistência passiva ou ativa da iniciativa privada, da estrutura manicomial, da burocracia estatal e do conservadorismo psiquiátrico"11. O desejo de "uma sociedade sem manicômios", construído neste contexto, aponta para a necessidade do envolvimento da sociedade na discussão e encaminhamento de questões relacionadas à doença mental e à assistência psiquiátrica. De lá para cá, o Movimento vem organizando no dia 18 e ao longo do mês de 
maio, o Dia da Luta Antimanicomial, com inúmeras atividades culturais, artísticas e científicas nos estados, em muitas cidades do país, com o objetivo de sensibilizar e envolver novos atores sociais para a questão. Dezenas de associações de familiares, de voluntários e de usuários de serviços psiquiátricos foram organizadas e outras deixaram de existir nessas duas décadas. O protagonismo dos usuários e familiares no Movimento tem crescido e amadurecido através do tempo fazendo lideranças profissionais muitas vezes se esquecerem de suas funções de cuidar para que esses segmentos tenham suporte para seguirem se desenvolvendo como sujeitos de suas histórias. Da mesma forma, inúmeras entidades da sociedade civil passaram a incluir o tema em seus debates e pautas de atuação.

\section{A I Conferência: pioneira e tutelada}

A 1 $1^{\text {a }}$ Conferência Nacional de Saúde Mental, 1987, organizada pela Coordenação de Saúde Mental do Ministério da Saúde e realizada no Rio de Janeiro, não teve a participação da sociedade civil, trabalhadores, usuários e famílias na sua organização porque à época isso não se cogitava. Tudo centralmente organizado, com grande esforço de setores contra hegemônicos do governo e uma grande sede de participação social dos diversos segmentos de base interessados. Não deu outra: ali se exercitou uma tomada de poder pela sociedade civil. Perverteu-se o estabelecido. Todo o Programa da Conferência organizada como se fora um Congresso Psiquiátrico cai por terra para dar lugar a uma assembléia popular conduzida por uma mesa diretora escolhida pela maioria. Também foi esse o critério para escolher uma relatoria representativa das cinco regiões do país. Primeiro exercício democratizante na definição da política de saúde mental para o país, a I Conferência representa, portanto, o início do desconstruir no cotidiano das instituições e da sociedade as formas arraigadas de se lidar com a loucura e a prescrição da desinstitucionalização como estratégia de reversão da exclusão dos loucos da cena pública ${ }^{22}$.

A partir dos anos setenta, em São José do Murialdo, no Rio Grande do Sul, uma experiência pioneira de saúde mental na atenção primária se desenvolvia e formava pessoas para essa nova prática. E Campinas, ainda na década de 70, implanta na cidade um programa de Saúde Mental nas unidades básicas de saúde que ainda permanecem em várias unidades, recicladas por gestões criativas que se sucederam. Entretanto, é na cidade de São Paulo, que o encontro de Luiz Cerqueira, então coordenador de Saúde Mental do estado e Guilherme Rodrigues da Silva, Professor Titular da Medicina Preventiva da USP e grande pensador da saúde coletiva brasileira, que aparece em 1973 um projeto experimental de Saúde Mental na Atenção Primária nos Distritos de Pinheiros, inicialmente, depois Butatã, na zona oeste da cidade, que foi semeador de um modelo de atenção integral e territorial que formou pessoas, penetrou a mídia e influenciou a política pública para a área na medida do avanço da democratização no estado e no país. Esse programa modelar para a atenção primária em saúde mental foi embrião da inflexão comunitária nos “anos Montoro", (1983-1987) com 91 equipes de psiquiatras, psicólogos e assistentes sociais trabalhando em Centros de Saúde do estado. Acompanhou-se ainda da chamada "ambulatorização" da saúde mental, transformando antigos e burocráticos ambulatórios (psicofármacos + guias de internação + estatísticas) em 22 centros comunitários de saúde, com seus programas de intensidades mínima, média e máxima, mantendo o nome de Ambulatórios de Saúde Mental por força de um movimento corporativo de seus funcionários, cunhando a expressão "ambulatorização" para aqueles que seriam embriões dos futuros Centros de Atenção Psicossocial - CAPS, para onde muitos deles foram lentamente se transformando e hoje estão cadastrados como tal, enquanto outros desapareceram substituídos por novos modelos.

O surgimento de experiências institucionais bem-sucedidas na arquitetura de um novo tipo de cuidado em saúde mental pipocava em vários pontos do país. Duas delas são consideradas "marco inaugural e paradigmático" de uma nova prática de cuidados: o Centro de Atenção Psicossocial Professor Luiz da Rocha Cerqueira, no Distrito da Bela Vista, na cidade de São Paulo; e a intervenção na Casa de Saúde Anchieta, realizada pela administração municipal de Santos, em São Paulo, como um projeto mais amplo e radical de desinstitucionalização no país.

\section{A origem dos CAPS}

O CAPS Luiz Cerqueira nasce em 1987 e é identificado como "marco inaugural" de um modo de cuidar que considera o sujeito em sofrimento como estruturante de uma "clínica ampliada" que o articula no seu território e não o enclausura para tratá-lo. Tal clínica teve na psicanálise, no uso racional dos psicofármacos e nas práticas de inclu- 
são social, o seu tripé de funcionamento. Tornouse o exemplo de um novo modelo de cuidado em Saúde Mental, construindo um modo de cuidar, sobretudo de pessoas psicóticas, mas também de não psicóticas, das suas famílias, de suas moradias, de suas artes, do seu trabalho, da sua renda... no território. Pacientes psiquiátricos graves exigem "condições terapêuticas que inexistem nos ambulatórios e hospitais psiquiátricos" tradicionais ${ }^{2}$. Pensado na sua criação para funcionar diuturnamente, o que jamais conseguiu, pode instituir uma usina produtora de encontros e trocas intersubjetivas que se tornou nacional pela sensibilidade do Coordenador de Saúde Mental à época, Domingo Sávio Nascimento Alves, com as portarias 189/91 e 224/92 do Ministério da Saúde e realçada como política pública no país na portaria ministerial 336/2001 e instrumentos normativos subsequentes, já na gestão exitosa de Pedro Gabriel Godinho Delgado ${ }^{23}$.

\section{Santos como ousadia}

Já a experiência santista nasceu da intervenção pública de uma administração municipal eticamente comprometida com uma gestão democrática e popular que elege a desinstitucionalização de um manicômio - a Casa de Saúde Anchieta - como o marco inicial de construção da política de saúde mental daquele município. A intervenção, o desejo e a vontade política da equipe gestora foram motivadas por denúncias de mortes, superlotação, abandono e maus-tratos que logo se confirmaram. O trabalho determinado de uma equipe pode, em pouco tempo, deslocar o eixo do cuidado para o território organizado em torno dos então criados Núcleos de Atenção Psicossocial (NAPS) em cada Distrito da cidade. Já nasceram centros comunitários de Saúde mental diuturnos, funcionando vinte e quatro horas ao dia, sete dias na semana. Foi a mais radical experiência de um modelo substitutivo aos manicômios no país, conduzida por David Capistrano, Roberto Tykanori, Fernanda Néscio, Antonio Lancetti e muitos outros. Cobria toda a cidade de quinhentos mil habitantes e fechou o manicômio lá existente, substituído por uma rede diversificada de dispositivos.

Descontinuidades e recuos nas políticas em estados e municípios fizeram com que a trajetória dessas experiências não tivessem um crescimento linear, mas seguramente influenciaram várias experiências singulares e exitosas em Campinas, Angra dos Reis, São Lourenço do Sul, Betim, Aracajú, Feira de Santana, Belo Horizonte,
Sobral, Fortaleza e outras tantas, na direção da superação de manicômios.

\section{Os anos 90 - A Reforma como política pública consentida}

Em 1989, o deputado Paulo Delgado (PTMG) apresentou o projeto de lei $n^{\circ} 3.657 / 89$, que viria a ser conhecido como a Lei da Reforma Psiquiátrica. O projeto era simples, com três artigos estruturantes: o primeiro impedia a construção ou a contratação de novos hospitais psiquiátricos pelo poder público; o segundo previa o direcionamento dos recursos públicos para a criação de "recursos não-manicomiais de atendimento"; e o terceiro obrigava a comunicação das internações compulsórias à autoridade judiciária $^{24}$. Depois de aprovado na Câmara dos Deputados, o projeto completou onze anos de substitutivos e postergações no Senado para de lá sair em 1999, numa articulação do parlamentar proponente, do Ministério da Saúde e do movimento antimanicomial. Voltou à Câmara já como projeto substitutivo para nova rodada de negociações, aprovação final e homologação pelo Presidente da República somente em abril de 2001. Grandes, polêmicos, apaixonados e frutíferos debates em todo o país em torno de uma lei, talvez tenha sido o maior subproduto nessa longa quarentena. Enquanto isso, uma avalanche de movimentos por mudança de legislação dos direitos dos enfermos mentais pipocou em muitos lugares em projetos de leis estaduais e municipais similares. Começou pelo Rio Grande do Sul e contagiou o país: mais seis estados e o Distrito Federal.

Se, ao longo dos anos 1980, o Movimento da Reforma Psiquiátrica inicia uma estreita relação com os movimentos sociais, nos anos 90 solidifica essa união. E é o emergente Movimento da Luta Antimanicomial, a partir do seu I Encontro em Salvador, Bahia em 1993, que mais tem estado presente nos rumos da $R P B$ nessas últimas décadas, apesar de todas as cisões e disputas internas.

O Movimento da Reforma Psiquiátrica é mais amplo. Incorpora a militância do Movimento da Luta Antimanicomial e de suas dissidências, mas também setores contra-hegemônicos de governos, sociedade civil, corporações da área, usuários, familiares, Universidades, aparelhos formadores e outros. Foi importante e decisivo para a consolidação de um projeto de saúde com pretensões de acessibilidade universal, reorientação da Saúde Mental no Brasil e a aprovação da sua Lei Federal 10.216/2001. Entretanto o início da ten- 
são dos movimentos sociais com os executores públicos da Reforma no interior do Estado (diferente do que aconteceu em outros países, como Itália e Canadá, onde eram os mesmos atores que reclamavam os que construíam as alternativas substitutivas ao manicômio, com forte engajamento ético-político, clínico, e de reabilitação psicossocial), desgastes, lutas intestinas e prejuízos para sua sustentabilidade tem sido a tônica da relação movimento antimanicomial \& poder executivo, com poucas exceções. E ao deslocar seu foco de luta, a $R P B$ começa a padecer do mesmo mal que acometeu a Reforma Sanitária - afastarse ou ser afastada do movimento social. Depositam-se nos que ocupam circunstancialmente funções de poder todas as esperanças para, a seguir, isolá-los de toda a força, vitalidade e princípio de realidade que somente os sujeitos reais e concretos, nos seus locais de ação podem nutrir. De outro lado, a oposição, a tensão, o questionamento e as críticas às políticas executadas pelo Estado, vindas do movimento social, passam a ser vistas como ataque ou obstáculo ao processo de Reforma pelos que a estão executando. Talvez nesse pêndulo esteja a força da radicalidade e da prudência necessárias à sobrevida do movimento.

Momento importante na constatação da tensão dos diferentes grupos envolvidos no processo da Reforma e negociação bem conduzida por um gestor público aconteceu na II Conferência Nacional de Saúde Mental “a democrática”, realizada em Brasília em 1992. É um marco histórico da reforma psiquiátrica brasileira com intensa participação dos segmentos sociais envolvidos, onde já 20\% dos delegados à conferência foram os usuários e familiares. O relatório final da conferência foi adotado como diretriz oficial para a reestruturação da atenção em saúde mental no Brasil nas gestões de Domingos Sávio Alves, que alquimicamente a conduziu, e nas que se seguiram (Eliane Seidl, Alfredo Schechtman, Ana Pitta, Pedro Gabriel Delgado). As recomendações gerais sobre o modelo de atenção enfatizavam o território e a corresponsabilidade no cuidado como forma de garantir "o direito dos usuários à assistência e à recusa ao tratamento, bem como a obrigação do serviço em não abandoná-los à própria sorte" 25 .

As análises existentes convergem ao apontar que o processo da Reforma no país não consistiu em um desmantelamento da rede hospitalar, mas na sua transformação para alternativas não hospitalares ${ }^{19}$. Na primeira metade da década de 1990, foram inaugurados quase cem serviços de atenção diária que seguiu crescendo inercialmen- te. Na ocasião, considerava-se que a substituição asilar vinha acontecendo "de maneira inequívoca e regular no Brasil nos últimos dez anos"10, e que se podia esperar uma aceleração do processo. Por razões óbvias deixo de detalhar o período dos anos 1998-2000, mas cabe mencionar os seguintes fatos: a Lei 10.216 sai do Senado e retoma a tramitação na Câmara (1999), recursos para os primeiros 400 CAPS (1999), portarias e recursos para os Serviços Residenciais Terapêuticos (2000); incentivo-bônus para a desinstitucionalização (1999) baseado no Programa de Apoio à Desinstitucionalização $(\mathrm{PAD})^{26}$ que a gestão seguinte pôde melhor operacionalizar com a Lei "De volta pra casa"23; psicofármacos básicos e de alto custo (1999), e o negociado retorno da Comissão Nacional de Saúde Mental no Conselho Nacional de Saúde (1999) que havia extinguido a Comissão de Reforma Psiquiátrica em 1998, esteio da participação do movimento social na política nacional de Saúde Mental.

\section{Os anos 2000 - A Reforma legal}

Pode-se dizer que o avanço mais consistente da reforma psiquiátrica brasileira acontece nessa década. Um arcabouço normativo importante trata da expansão da rede comunitária e do controle dos hospitais ${ }^{23}$, onde as Portarias 336 e 189 expandem os CAPS e duas portarias, 106 e 1.220 , ambas de $2000^{23}$, instituem os "serviços residenciais terapêuticos (SRT)" a fim de viabilizar a reinserção social na comunidade dos moradores de hospitais cronicamente internados. Aliadas às portarias que deram existência institucional aos CAPS e NAPS (336/2001), se constituem em importantes instrumentos normativos da Reforma. Começa então a era mais vigorosa para a gestão da política de saúde mental no Brasil (2000 - 2011) onde uma equipe dedicada, sob a coordenação de Pedro Gabriel Delgado, liderança respeitada do movimento da luta antimanicomial, geriu de forma competente os interesses da Reforma Psiquiátrica, por uma década.

Ainda em 2001, e sob o marco da nova Lei 10.216/2001, aconteceu a III Conferência Nacional de Saúde Mental, em Brasília, com grande participação popular e democrática. Representação ampla de todos os setores envolvidos, e precedida por centenas de conferências municipais, regionais e estaduais, em todo Brasil. Alí já aparece a complexidade do campo da Reforma Psiquiátrica claramente delineado: enfrentamento do estigma; reorientação do modelo assistencial com garantia de equidade de acesso; direitos 
e cidadania com prioridade para a formulação de políticas que fomentem a autonomia dos sujeitos; expansão do financiamento e controle social. Foi uma festa de participação democrática e representação social com mais de dois mil participantes, convidados e testemunhas nacionais e internacionais, onde se pôde ratificar e criticar elementos contidos na Lei.

Uma vez homologada a Lei 10.216 em abril de 2001 pelo Presidente da República, fica prescrita a elaboração de "política específica de alta planejada e reabilitação psicossocial assistida" para o paciente "há longo tempo institucionalizado" e para as situações de "grave dependência institucional". Menciona os chamados "serviços residenciais terapêuticos" e todos os dispositivos assistenciais para cuidar em liberdade. A lei foi o ponto culminante de um processo de normatização da assistência que vinha sendo implementada com o desenho da Reforma através das portarias ministeriais e da indução financeira para tal fim. A substituição progressiva dos manicômios e a implementação da rede de atenção psicossocial que o tornará prescindível, está descrita na lei. De modo não linear e simétrico, e com muitas resistências, essa rede vem sendo construída no território nacional (vide Tabela 1).

\section{Os desafios atuais... dez anos depois...}

Passados dez anos da homologação da Lei 10.216, o que temos como tendência nessa última década?

A luz de todas as nuances de enfrentamento do estigma que envolve a questão da enfermidade mental e o uso de substâncias psicoativas, avançamos muito nas prescrições e nas diretrizes do Ministério da Saúde, da Justiça e Direitos Humanos, da Cultura, do Trabalho, para a área. Tal avanço prescritivo, presente na Legislação, nos relatórios das Conferências, nas portarias ministeriais, até mesmo em manifestações públicas de Presidentes, Governadores, Prefeitos e Secretários não se fazem acompanhar, entretanto, de ações consequentes que viabilizem o dito ou o escrito na intensidade na qual se faz necessária. Mesmo em governos democráticos onde tivemos lideranças expressivas do Movimento da Reforma Psiquiátrica ocupando postos de real poder de decisão (refiro-me a Ministro e a cargos de segundo e terceiro escalão), a desqualificação da subjetividade humana nas políticas públicas é um fato. A sistemática negação de direitos que a condição marginal dos usuários de instituições psiquiátricas e de substâncias psicoativas parece determi- nar, posterga e opacifica qualquer demonstração de factibilidade para as políticas de saúde mental e intersetoriais prescritas. A exclusão, a restrição de recursos é a política hegemônica dos governos municipais e estaduais, desobedecendo assim às diretrizes nacionais da política de saúde mental. Sem consenso, o que ganha relevo em alguns momentos na agenda do governo federal, se dilui nas demais esferas de governo, chegando aos cidadãos de um modo pálido, em ações pouco potentes, com pequena margem de resolutividade, com equipes que flutuam na dependência do prefeito municipal em exercício.

Como fato novo nesses últimos dez anos temse a entrada orgânica do enfrentamento do uso prejudicial das substâncias psicoativas nos governos da União, dos estados e dos municípios. Área que sempre mereceu referências da sua importância epidemiológica sem jamais ter merecido uma consequente resposta política e assistencial de fato, entra nessa última gestão como prioridade no discurso presidencial, particularmente referida ao uso do Crack. Política se faz com ira, amor e... dinheiro. Ira para indignar-se por alguma situação negligenciada ou aviltada; amor ético e universal para abraçar a causa que se pretende intervir e encontrar a estratégia mais sublime e adequada de intervir; e, dinheiro, para dar consequência às prescrições e desejos de enfrentamento do problema identificado. A lei e o Decreto Presidencial, e as consequentes portarias ministeriais e interministeriais, liberaram recursos financeiros para o enfrentamento do crack, fechando assim o ciclo que prescreve uma intenção de governo para uma política de Estado com a consequência financeira para executá-la. $\mathrm{O}$ grande desafio agora para gestores e trabalhadores que operam as redes assistenciais é de como contemplar as necessidades reais e concretas das pessoas usuárias de drogas nos sistemas de cuidados. Quais respostas vão ser produzidas no imediato?

Tomando como referência crianças, adolescentes, adultos e idosos em situação de rua, situação comum entre os que o uso da droga desestruturou laços sociais e familiares, se observa um descompasso entre o prescrito e o real. Para um grande avanço normativo, com portarias e editais prescrevendo e se dispondo a financiar a rede de cuidados, encontramos poucas iniciativas nos estados e municípios, onde as pessoas vivem cotidianamente. As academias se acomodam nos serviços ambulatoriais diurnos que melhor se adequam aos seus ritos acadêmicos. Nesse vazio de alternativas oficiais públicas de rede assistencial continente, as "comunidades terapêuticas" 
seguem se insinuando na ocupação desse espaço diuturno no SUS. Se a vida é crônica, precisamos aprender a cuidar dos nossos usuários cronicamente, em liberdade, diuturnamente, oferecendo-lhes chances de sobrevida digna nos diversos cenários em que a vida de todos os humanos se dá: moradia, locais de tratamento e reabilitação, trabalho, escola, renda, lazer, etc.

A solução das "comunidades terapêuticas", na sua maioria oferece apenas o enclausuramento do problema, na ausência de uma ação mais efetiva e eficaz do Estado. O movimento da Reforma Psiquiátrica inclui tais instituições entre as asilo-manicomiais que precisam ser substituídas progessivamente. A Reforma Psiquiátrica Brasileira segue defendendo ações efetivas em rede na Atenção Básica, nos Ambulatórios Especializados, nos CAPS AD III, nas Unidades Residenciais Transitórias, nos Serviços Residenciais Terapêuticos, nos leitos em Hospitais Gerais e nas pequenas enfermarias especializadas. Ainda enfatiza os Pontos de Encontro, os Centros de Convivência, as Oficinas de Geração de Renda e Trabalho e o "gerenciamento de casos" nas comunidades, baseados na lógica de redução de danos. Defende ainda ações intersetoriais de inclusão social no trabalho, na escola, nas artes, nos esportes, na cultura e a produção de chances de novos protagonismos sociais que ocupem o lugar das drogas nos projetos de vida dos usuários.

A Reforma Psiquiátrica tenta dar ao problema uma resposta não asilo-confinante, reduzindo danos e desvantagens sociais que trazem o confinamento associado aos transtornos mentais e ao uso de substâncias psicoativas. O sucesso da reforma reside na percepção da necessidade da construção de um amplo espectro de cuidados para sustentar a existência de pessoas/usuários/pacientes que, sem isso, estariam condenados a perambular pelas ruas abandonados, ou, a vegetar em manicômios em longas internações. Foram criados serviços capazes de ser uma referência institucional permanente de cuidados (os CAPS), serviços residenciais terapêuticos e outros serviços ambulatoriais de referência. Foram incorporados ao campo da saúde cuidados e procedimentos tais como renda (o auxílio Reabilitação De volta pra casa, Lei Federal), trabalho protegido (Programa geração de renda e trabalho, MS/MT), lazer assistido (Pontos de cultura, MINC/MS) e outras formas de intervenção intersetorial ampliada. É constituída uma rede de atenção psicossocial que diz respeito à própria existência do sujeito assistido ${ }^{8}$.
Em seu livro, intitulado "A Reforma Psiquiátrica", Manuel Desviat ${ }^{27}$ dedica um capítulo à reforma psiquiátrica brasileira, que considera um dos mais frutíferos, promissores e vigorosos processos de transformação no campo da saúde mental e da psiquiatria no mundo. Benedetto Sarraceno, que frequenta o Brasil desde 1987 e que acompanhou de perto, em muitos estados brasileiros, os movimentos da Reforma Psiquiátrica, como pesquisador do Instituto Mario Negri e como Diretor do Departamento de Saúde Mental e abuso de Drogas da Organização Mundial de Saúde, em diferentes ocasiões pode externar sua opinião da Reforma Psiquiátrica Brasileira ser das mais profícuas experiências no mundo ${ }^{28}$.

Estamos falando em desinstitucionalização responsável, isto é, tratar o sujeito em sua existência e em relação com suas condições concretas de vida. O tratamento deixa de ser a exclusão em espaços de violência e morte social para tornar-se criação de possibilidades concretas de subjetivação e interação social na comunidade.

As celebrações do 18 de maio nos alertam para o que deve acontecer: inclusão social da loucura em liberdade. Chama a atenção para os desafios próprios do crescimento do bem sucedido movimento da Reforma Psiquiátrica Brasileira no interior de um estado burocrático, refratário a inovaçoes, e a radicalidade que a mudança do modo de cuidar requer. $\mathrm{O}$ doente mental, antes excluído do mundo dos direitos e da cidadania, se transforma em sujeito cidadão e não objeto de políticas públicas. Sendo esta uma questão mais ético-política e cultural do que técnica, o futuro da Reforma Psiquiátrica Brasileira está na esperança que os usuários, familiares, trabalhadores - esses novos protagonistas que amadurecem e se renovam a cada dia - encontrem modos mais sensíveis de reduzir os danos causados pelas nossas instituições e nossas escolhas insensatas.

\section{Agradecimentos}

Alfredo Schechtman, Sonia Barros e Maria das Graças Miranda Ribeiro. 


\section{Referências}

1. Schopenhauer A. Como vencer um debate sem precisar ter razão. Rio de Janeiro: Topbooks; 2003.

2. Goldberg JI. Clínica da psicose: um projeto na rede pública. Rio de Janeiro: Te-Corá/Instituto Franco Basaglia; 1994.

3. Goldberg JI. Cotidiano e Instituição: Revendo o tratamento de pessoas com transtorno mental em instituições públicas [tese]. São Paulo: Depto.de Medicina Preventiva da Universidade de São Paulo; 1998.

4. Pitta AMF, Silva Filho JF, Souza Campos GW, Lancman S, Kinoshita RT, Cavalcanti MT, Valentini WH. Determinantes da qualidade de serviços de saúde mental em municípios brasileiros - Estudo da satisfação com os resultados das atividades desenvolvidas por pacientes, familiares e trabalhadores de serviços. J Bras Psiquiatr 1995; 44(9):441-452.

5. Almeida PF. Avaliação de serviços em saúde mental: o desafio da produção de indicadores para a atenção psicossocial [dissertação]. Rio de Janeiro: Escola Nacional de Saúde Pública; 2002.

6. Tenório F. A reforma psiquiátrica brasileira, da década de 1980 aos dias atuais: história e conceito. História, Ciências, Saúde - Manguinhos 2002; 9(1):25-59.

7. Wetzel C, Kantorski L. Avaliação de serviços em saúde mental no contexto da Reforma Psiquiátrica. Texto Contexto Enferm 2004; 13(4):593-598.

8. Yasui S. Rupturas e encontros: desafios da reforma psiquiátrica brasileira. Rio de Janeiro: Editora Fiocruz; 2010.

9. Surjus L, Togni S, Onoko R. A avaliação dos usuários sobre os Centros de Atenção Psicossocial (CAPS) de Campinas, SP. Revista Latinoamericana de Psicopatologia fundamental 2011; 14(1):122-133.

10. Brasil. Ministério da Saúde (MS). Secretaria de Atenção à Saúde. DAPE. Coordenação Geral de Saúde Mental. Reforma psiquiátrica e política de saúde mental no Brasil. Documento apresentado à Conferência Regional de Reforma dos Serviços de Saúde Mental: 15 anos depois de Caracas.Brasília: Organização Pan Americana de Saúde; 2005.

11. Bezerra Jr. B. Desafios da Reforma Psiquiátrica no Brasil. PHYSIS: Rev Saude Colet 2007; 17(2):243-250.

12. Saraceno B. Reabilitação Psicossocial. In:Pitta AMF, organizador. $3^{a}$ ed. Reabilitação psicossocial no Brasil. São Paulo: Hucitec; 2010.

13. Domingos SA. Comunicação pessoal à autora em junho de 2011 .
14. Mari J, Thornicroft G. A luta antimanicomial e a psiquiatria. Folha de São Paulo 201018 maio p.2.

15. Pitta-Hoisel AM. Sobre uma política de Saúde Mental [tese]. São Paulo: Depto. de Medicina Preventiva, FMUSP; 1984

16. Delgado PGG. No litoral do vasto mundo: lei 10.216 e a amplitude da reforma psiquiátrica. In: Venâncio A, Cavalcanti MT, organizadores. Saúde mental: campo, saberes e discursos. Rio de Janeiro: Edições Ipub-Cuca; 2001

17. Amarante P. Loucos pela vida: a trajetória da reforma psiquiátrica no Brasil. 2a ed. Rio de Janeiro: Editora Fiocruz; 1998

18. Lobosque AM. Clínica em movimento: por uma sociedade sem manicômios. Rio de Janeiro: Garamond; 2003.

19. Amarante P. Novos Sujeitos, Novos Direitos: O Debate sobre a Reforma Psiquiátrica no Brasil. Cad Saude Publica 1995; 11(3):249-263.

20. Resende H. Política de saúde mental no Brasil: uma visão histórica. In: Tundis S, Costa N, organizadores. Cidadania e loucura: políticas de saúde mental no Brasil. Petrópolis: Vozes; 1987.

21. Alves DS. O "ex" tentando ver o futuro. Cadernos Ipub 1999; 14:21-30.

22. Luzio CA, Yasui S. Além das portarias: desafios da política de saúde mental. Psicol estud 2010; 15(1):1726.

23. Brasil. Ministério da Saúde (MS). Secretaria-Executiva, Secretaria de Atenção à Saúde. Legislação em saúde mental: 1990-2004. 5a ed. ampl. Brasília: Ministério da Saúde (MS); 2004.

24. Vasconcelos EM. Do hospício à comunidade. Belo Horizonte: SEGRAC; 1992.

25. Brasil. Ministério da Saúde (MS). Relatório Final da $2^{\underline{a}}$ Conferência Nacional de Saúde Mental, Brasília: Coordenação de Saúde Mental, Ministério da Saúde (MS); 1994.

26. Alves DSN. Por um programa brasileiro de apoio à desospitalização: o programa de apoio à desospitalização (PAD) enquanto estratégia nacional de reabilitação. In: Pitta AMF, organizador. Reabilitação psicossocial no Brasil. $3^{a}$ ed. São Paulo: Hucitec; 2010. p. 27-30

27. Desviat M. A Reforma Psiquiátrica. Rio de Janeiro: Fiocruz; 2002.

28. Declaração de Caracas, 20 anos depois. [acessado 2011 jun 21]. [documento na Internet]. Disponível em: http://www.saude.gov.br/saudemental 